Metallophysics and Advanced Technologies

Металофіз. новітні технол.

Metallofiz. Noveishie Tekhnol.

2019, vol. 41, No. 8, pp. 1103-1119

https://doi.org/10.15407/mfint.41.08.1103

Reprints available directly from the publisher
(C) 2019 G. V. Kurdyumov Institute for Metal Physics, National Academy of Sciences of Ukraine Published by license under

the G. V. Kurdyumov Institute for Metal PhysicsN.A.S. of Ukraine Publishers imprint. Printed in Ukraine.

PACS numbers: 75.20.En, 81.05.Bx, 81.40.Rs, 85.70.Ay, 91.60.Pn

\title{
High-Gradient Magnetic Separation Method for Weakly Magnetic Particles: an Industrial Application
}

\author{
Chouki Farsi, Salah Amroune, Mustafa Moussaoui", \\ Barhm Mohamad"* and Houria Benkherbache
}

\author{
Pôle Universitaire de M'sila, \\ Laboratoire de Matériaux et Mécanique des Structures, \\ Université Mohamed Boudiaf de M'sila, \\ BP 166 M'sila 28000, Algérie \\ "Université Ziane Achour de Djelfa, \\ BP 3117 Djelfa 17000, Algérie \\ **Faculty of Mechanical Engineering and Informatics, \\ University of Miskolc, \\ H-3515 Miskolc, Hungary
}

The high-gradient magnetic separation process is a technique used in heavy industries, particularly steel mills, to extract magnetic particles from mixtures. The difficulty of separating the slightly magnetic particles from the nonmagnetic ones lies in the distribution of the magnetic field and the fineness of their class to be separated. A use of different separation matrix profile is implemented, making it possible to act on the value of the gradient of the inhomogeneous magnetic field. Different matrixes are tested and the results obtained experimentally allows to choose the most efficient matrix form in the operation of extraction which increased by $11 \%$ in magnetic fraction yield, $15 \%$ iron content and $17 \%$ of extraction degree relative to the John's matrix. This matrix used is consistent with that cited in literatures. The separation technology used can extend its useful application to small particles from very weakly magnetic materials. Its exploitation will result in the method of reducing the degree of pollution and improvement the process of extraction of minerals that has an impact on the environment and on human

\footnotetext{
Corresponding author: Chouki Farsi

E-mail: Chouki.farsi@univ-msila.dz

Citation: Chouki Farsi, Salah Amroune, Mustafa Moussaoui, Barhm Mohamad, and Houria Benkherbache, High-Gradient Magnetic Separation Method for Weakly Magnetic Particles: an Industrial Application, Metallofiz. Noveishie Tekhnol., 41, No. 8: 1103-1119 (2019), DOI: 10.15407/mfint.41.08.1103.
} 
health as a result a high level of extraction.

Key words: magnetic matrix, high-gradient magnetic separation process (HGMS), gradient of magnetic field, magnetic particles.

Високоградієнтний процес магнітного розділення - метод, який використовується у важкій промисловості, особливо в сталеливарному виробництві, для виділення магнітних частинок із сумішей. Складність відділення слабомагнітних частинок від немагнітних полягає в забезпеченні необхідного розподілу магнітного поля та малих розмірах цих частинок. Використовуються різні види розділових матриць, що дозволяє впливати на величину градієнта неоднорідного магнітного поля. Різні матриці були протестовані і експериментально отримані результати дозволили вибрати найбільш ефективну форму матриці для вилучення частинок, що дозволяє збільшити на $11 \%$ вихід магнітної фракції, на $15 \%$ вміст заліза і на $17 \%$ ступінь вилучення відносно матриці Джона. Використовувана матриця відповідає описаній в цитованій літературі. Використана технологія розділення дозволяє розширити ї̈ корисне застосування на випадок дрібних частинок дуже слабких магнітних матеріалів. Використання даної технології дозволяє зменшити ступінь забруднення, поліпшує процес видобутку корисних копалин, який впливає на навколишнє середовище i здоров'я людини завдяки досягненню високого рівня екстрагування.

Ключові слова: магнітна матриця, високоградієнтний магнітний сепаратор, градієнт магнітного поля, магнітні частинки.

Высокоградиентный процесс магнитного разделения - метод, который используется в тяжёлой промышленности, особенно в сталелитейном производстве, для выделения магнитных частиц из смесей. Сложность отделения слабомагнитных частиц от немагнитных заключается в обеспечении необходимого распределения магнитного поля и малых размерах этих частиц. Используются различные виды разделительных матриц, позволяющих влиять на величину градиента неоднородного магнитного поля. Различные матрицы были протестированы и экспериментально полученные результаты позволили выбрать наиболее эффективную форму матрицы для извлечения частиц, что позволяет увеличить на $11 \%$ выход магнитной фракции, на $15 \%$ содержание железа и на $17 \%$ степень извлечения относительно матрицы Джона. Используемая матрица соответствует описанной в цитируемой литературе. Использованная технология разделения позволяет расширить её полезное применение на случай мелких частиц очень слабых магнитных материалов. Использование данной технологии позволяет уменьшить степень загрязнения, улучшает процесс добычи полезных ископаемых, который влияет на окружающую среду и здоровье человека благодаря достижению высокого уровня извлечения.

Ключевые слова: магнитная матрица, высокоградиентный магнитный сепаратор, градиент магнитного поля, магнитные частицы.

(Received October 2, 2018; in final version, May 12, 2019) 


\section{INTRODUCTION}

Magnetic separation is a physical separation process that separates materials according to their magnetic susceptibility. Since the process is based on physical rather than chemical properties, separations can be achieved while producing a minimum of secondary waste. Magnetic separation is a technique for removing scrap and concentrating iron ores. Numerous works on magnetic separation have been addressed published [1-3], which use describes various devices for mineral processing. Conventional magnetic separation devices are generally limited to the separation of highly magnetic materials, such as iron and magnetite. The provision of intense pulsed or fixed magnetic fields (greater than 5 or $10 \mathrm{~T}$ ) in laboratory is becoming more widespread and the fields of application are increasing. The effects of intense magnetic fields on matter are indeed many and sharpen the curiosity of researchers. Quantum effects [2], thermodynamic [3], mechanical [4, 5] imperceptible low field are observed in the material under strong magnetic field.

The industrial and environmental depollution treatment by magnetic separation is used in the purification processes of the desulphurisation of the coals used as fuel in the furnaces of thermal and electrical power plants. It involves reducing the ash and sulphide $\left(\mathrm{FeS}_{2}\right)$ content present in the coal mass. It is also used in the filtration of fluids in thermal or nuclear power plants for the production of electrical energy by extracting particular or corrosive products.

The development of the magnetic separation of the particles is based on the improvement of the gradient of $H$ field in $\left[\mathrm{kA} / \mathrm{m}^{2}\right]$, where $H$ is the intensity of the magnetic field in $[\mathrm{kA} / \mathrm{m}]$. This method of filtration of the pulp through layers of magnetic is used by several authors [612]. Notably Turkenich et al. [13] has shown that the choice of pole shapes plays a key role in obtaining a non-homogeneous magnetic field with a maximum value of the gradient. This inhomogeneity and uniformity of the field ensures even more the opening of the magnetic fraction. The latter helps the process of washing these magnetic fractions which continues the separation process; this is explained by the ease of penetration of water through the magnetic flocculates. This wash removes non-magnetic particles that stick to magnetic ones. The first filters were made by Turkenich et al. [13] in the form of steel grids. These poles consist of rapid demagnetization metal plates made of mild steel such as the cores of transformers are generally used at high-gradient separators. Currently these separators consist of a rotating part (rotor) where are placed the matrices of different profiles which will be magnetized, and a fixed part (stator) which creates the magnetic field with a very intense flux concentrated on the walls of the matrices separations during the magnetization period. The essential 
feature of the high-gradient separation is the closure of the electromagnetic system, where a very high induction is created in the electrotechnical steel ring cores that pass through the small volume of work through the dies. The selection of the shape and the dimensions of the elements of the matrix of the separator depend on the intensity of the field. With a relatively weak magnetic field separation can only be achieved if a poly-gradient medium is used which can improve the level of magnetic forces required for extraction. Virtually all types of highgradient matrices provide the required gradient magnetic field [14], so their shape is necessary to select the magnetic particles on the basis of mechanical properties and fluid flow regime. To obtain the level of magnetic force necessary for the extraction, with a relatively weak magnetic field it is necessary to use only a poly-gradient medium of the field. The possibility of its regeneration must be given great importance since the separation cycle is repeated each time. This regeneration can be explained by the rotation of the rotor which keeps the matrices of the separator in continuous rotation by carrying out the four operations at the same time, notably: the feeding of the separation matrices by the pulp (water + product); magnetization of this product found in matrices; washing the flocculants attracted and then glued to the internal separation surface; the demagnetization of the magnetic fraction. After this operation the separation cycle is repeated. A polygradient medium may be as: metal wool; a set of corrugated plates arranged in parallel; a set of parallel metal rods; a volume filled with metal balls.

On the one hand, it is necessary to increase the effective extraction surface of the magnetic particles, and on the other hand-maximum approximation of the radius of curvature of the elements of the extraction surface with respect to the particle size of the material recovered, according to the results of the studies, directed by Karmazin [15], the most effective dimensions of the particles that adhere on the magnetic surfaces are of the class $0.04-0.05 \mathrm{~mm}$, because these requirements are the most compatible with the wire wool son of $0.1 \mathrm{~mm}$ thick, used in poly-gradient separators (Sala separators, etc.) [15], however it has a low filtration rate, is quickly clogged by inclusions and hard nonmagnetic salts. The experiments show that even for small values of the strength of the magnetic field the metallic wool provides enough good extraction of the highly magnetic particles of the pulp [16]. On the other hand, the complex, the micro porous structure of the metal wool does not favour the release and the passage of the pulp, and the washing of the magnetite particles in the industrial conditions which are carried out under a large water pressure, which is expensive.

In addition, due to the constant reorientation of the magnetic field, the particles which are in a relatively free state on the surface of the accumulated layers acquire a rotating moment torque. When addition- 
al water is supplied, with discharge rotation of sterile and weakly magnetic particles becomes easy, which increases the quality of the concentrate. The details and the description of this phenomenon of rotation of the magnetic particles in the alternating magnetic field have been described in Refs. [17, 18].

The work presented is concerned with the analysis of the distribution of the field within the separation space for the different matrices used by a quantitative evaluation of the field gradient for each point between the separation poles. The end goal is to use this method in the steel mill of M'sila (Algeria) which produces iron from the products of recovery.

\section{EXPERIMENTAL MATERIAL AND PROCEDURES}

The apparatus used for the realization of the matrices is a highgradient separator of the laboratory of the National University of Kryvyi Rih (Ukraine), department of enrichment of useful minerals (Fig. 1). It consists of the coils of the separator of the laboratory (1); an opening for the location of the dies between the poles of the magnetic core (2); an outer core of the coils of the magnetic system for closures of the magnetic flux (3) and a mechanism for clamping the dies inside the magnetic poles (4).

There are five types of matrices used experimentally (Fig. 2) for high-gradient separation with magnetized flocculants forms.

After several experiments on the magnetized bodies, for example those represented on the Fig. $3, a-d$. We arrived at the final forms presented in Fig. 4, $a-c$. For the convenience of measurements and for a good distinction of the lines of the magnetic field we examined at the

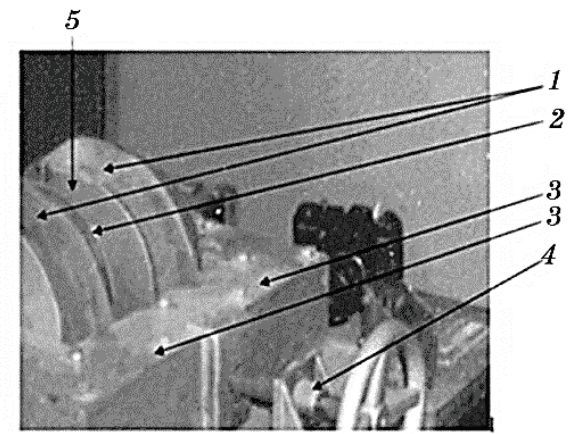

$a$

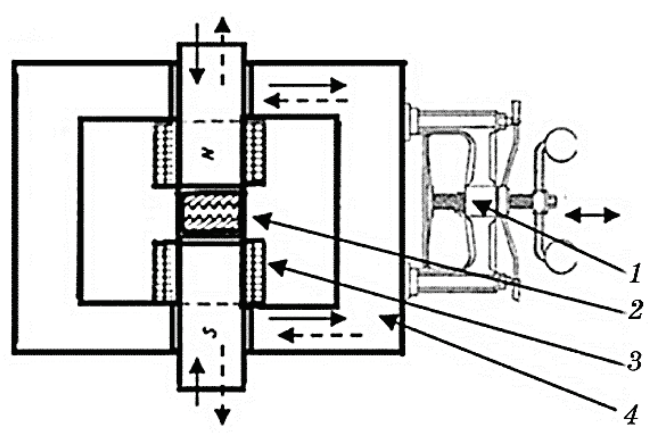

$b$

Fig. 1. High-gradient magnetic separator. Functional scheme $(a)$, kinematic scheme $(b)$. 


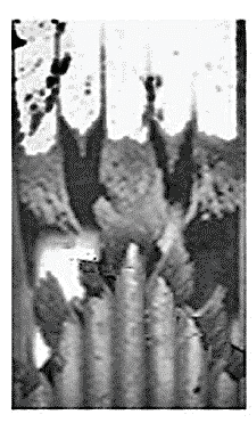

$a$

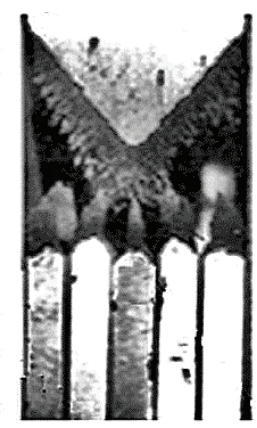

$b$

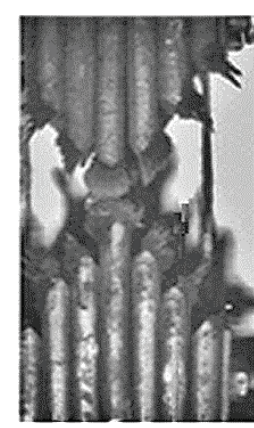

$c$

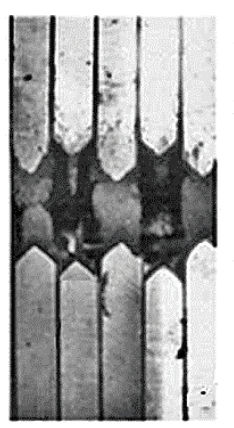

$d$

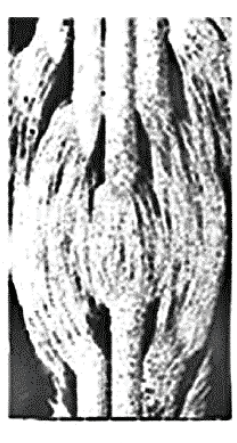

$e$

Fig. 2. Perspective view (a), views of the dies with the flocculates $(b-e)$.

beginning each group of teeth of different shapes in front poles of flat shapes.

There are several forms of matrices used for the high-gradients separators of the field one was considered and selected those which presented in Fig. 4.

The working angle of the magnetic poles becomes effective in separation if its value lies between $40-60^{\circ}$. According to the convenience and ease of construction in the present work, the angle of these poles is taken equal to $45^{\circ}$ for each group of teeth. From the view from above the distance between the measuring points is $5 \mathrm{~mm}$, in both directions to obtain the more or less exact gradient of the studied form.

Each selected matrix is introduced between the magnetic poles of the two magnetization coils and this before their DC power supply, and then the tightening is done by the screw system (Fig. $1, b$ ) and this after positioning the dies between these poles of the separator.

The next step is the measurement of the magnetic induction for each

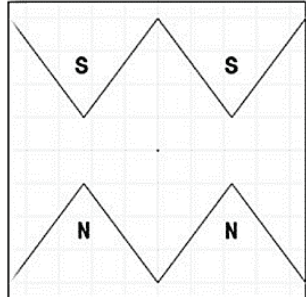

$a$

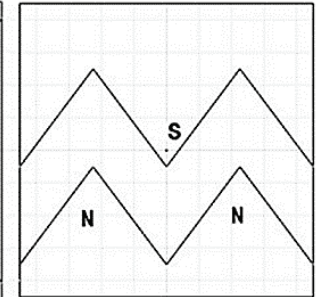

$b$

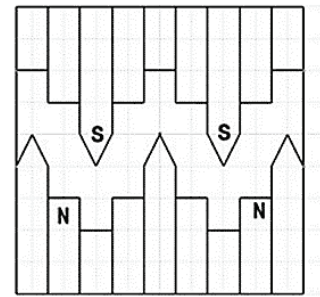

$c$

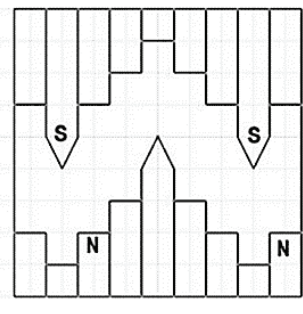

$d$

Fig. 3. Top views of the matrices used during the analysis of the magnetic field. John's matrices with opposite peaks facing each other (a), John's matrices with vertices of the North poles which are placed in front of the concave parts of the other poles $(b)$. Dies with 5 wide combined profiles for each tooth period $(c), 7$ thin combed dies for each tooth period $(d)$. 
$a$

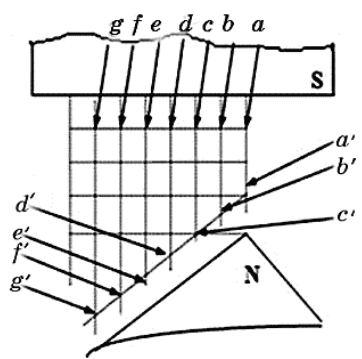

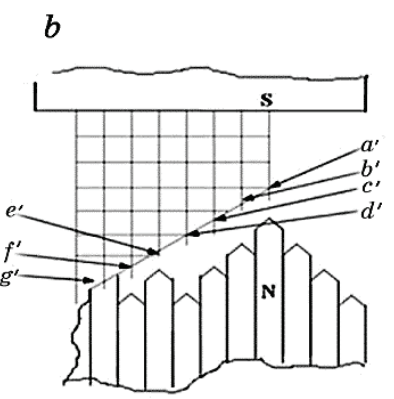

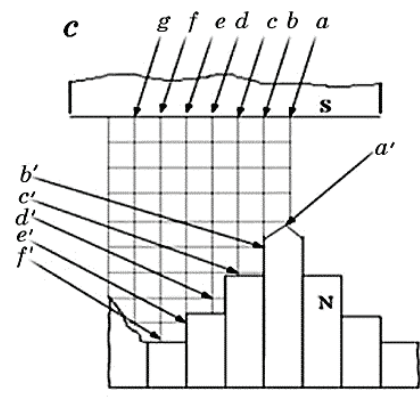

Fig. 4. Matrices used in the analysis of the magnetic field: $a$-John's matrices, $b$-proposed triangular tooth matrices, $c$-matrices with combined profiles.

of the shapes used in front of the flat poles to simplify the measurements sees Fig. 4. The magnetic induction measurement values are taken successively from the points $a, b, c, d, e, f, g$ to the points in front which are $a^{\prime}, b^{\prime}, c^{\prime}, e^{\prime}, f^{\prime}, g^{\prime}$ squares of the grids drawn between the different shapes of the poles as shown in the figures below Fig. 3 .

After obtaining the values of the magnetic inductions by a Teslameter, we computed the magnetic forces then the gradients of the field of these forces and then plotted the curves of the gradients according to the types and shapes of matrices.

\section{THEORETICAL STUDY: CONCEPT OF THE MAGNETIC FIELD}

It is clear that increasing the value of the magnetic field $H$ will increase the magnetic force both by increasing the magnetization of the particle and, in general, by increasing the value of the field gradient. However, it may be seen intuitively that the magnetic field gradient, that is, the distance in which the magnetic field changes by a significant amount will strongly affect the magnetic force.

In the case of a linear, homogeneous and isotropic material, the magnetic volume energy of magnetization acquired by a particle is given by the following relation $[19,20]$ :

$$
\varepsilon_{m}=-\frac{\chi \mu_{0}}{2} H^{2},
$$

where $\varepsilon_{m}-$ magnetic energy magnetization $\left[\mathrm{J} / \mathrm{m}^{3}\right], H-$ magnetic field, $\chi$-magnetic susceptibility $\left[\mathrm{m}^{3} / \mathrm{kg}\right], \mu_{0}$-vacuum permeability $[\mathrm{H} / \mathrm{m}]$.

The equation presented is a function of the term $\chi$ magnetic susceptibility (MS), which translates the capacity of anybody to acquire magnetization induced under the effect of a magnetic field. So that's the report $(M / H)$ with the magnetization $M$ in $[\mathrm{A} / \mathrm{m}]$, that is to say a field 
involved in a solid angle, and the field (induced) $H$. For diamagnetic materials, magnetic susceptibility $\chi$ is of the order of $-10^{-5}$ and of $10^{-3}$ for paramagnetic substances, susceptibilities of up to $10^{6}$ for ferromagnetic materials are even more noticeable.

There are several types of magnetism: when $\chi$ is negative, we say that the body in which the magnetization appears is diamagnetic; when $\chi$ is zero, there is a vacuum; when $\chi$ is positive, the body is called paramagnetic; when $\chi$ is positive and very high, the paramagnetic body is called ferromagnetic.

The force associated with the magnetic energy magnetization volume is derived from this energy by the relation [19, 20]:

$$
\mathbf{f}_{m v}=\operatorname{grad} \varepsilon_{m},
$$

where $\varepsilon_{m}$ magnetic energy magnetization $\left[\mathrm{J} / \mathrm{m}^{3}\right], \mathbf{f}_{m v}$ is volume magnetic force $\left[\mathrm{N} / \mathrm{m}^{3}\right]$.

A particle always seeking to minimize its energy, its behaviour will vary according to the nature of its magnetism: a paramagnetic particle $(\chi>0)$ will be attracted to intense fields while a diamagnetic particle $(\chi<0)$ will be drawn to the weak field areas.

The expression of the volume force can be obtained according to the gradient of the magnetic field [19, 20]:

$$
\mathbf{f}_{m v}=\frac{\chi \mu_{0}}{2} \operatorname{grad} H^{2}
$$

where $\chi$-magnetic susceptibility $\left[\mathrm{m}^{3} / \mathrm{kg}\right], \mu_{0}$-vacuum permeability [H/m], H-magnetic field [A/m].

Consider a spherical particle located in a field, along the axis of symmetry and for values of applied magnetic field $H_{0}$ less than the bulk saturation value of the ferromagnetic wire $H_{s}$, the magnetic field is given by the expression:

$$
H=H_{0}\left(1+\frac{a^{2}}{r^{2}}\right),
$$

where $H_{0}$-magnetic field of middle [A/m], $r$ is the center of the wire, $a$ is the radius of the wire (Fig. 5).

The magnetic field gradient for applied fields $H_{0}$ less than $H$, along the axis at the particle, is given by the expression:

$$
\frac{d H}{d r}=-2 H_{0} \frac{a^{2}}{r^{3}}
$$

where $H_{0}$ is induction of the magnetic field of middle [T], if the magnetization of the particle is small. The radius of the wire is $a$, the dis- 
tance from the centre of the wire is $r$. These equations describe a ferromagnetic cylinder in an applied field $H_{0}$.

We may now consider the dependence of the magnetic force on the particle diameter for magnetic separators which are gradientmatched, that is, in which the radius of the wire is equal to three times the particle radius. In this case may be rewritten as:

$$
F_{m}=1.84\left(\chi_{p}-\chi_{m}\right) H_{0}^{2} b^{2},
$$

where $\chi_{p}$ is a magnetic susceptibility of particle $\left[\mathrm{m}^{3} / \mathrm{kg}\right], \chi_{m}$ is magnetic susceptibility of middle $\left[\mathrm{m}^{3} / \mathrm{kg}\right], H_{0}$ is a magnetic field of middle $[\mathrm{A} / \mathrm{m}], b$-radius of particle $[\mathrm{m}]$.

The forces in magnetic separators which compete with the magnetic forces and act on all of the particles which travel through the separator are those of gravity, hydrodynamic, drag, fraction, and inertia. We will consider only gravitational and hydrodynamic drag forces which are important in determining the characteristics of many magnetic separators, including high-gradient devices. For spherical particle of radius $b$ and density of particle $\rho_{\mathrm{p}}$ the gravitational or buoyant force is given by:

$$
F_{g}=\frac{4}{3} \pi b^{3}\left(\rho_{p}-\rho_{f}\right) g,
$$

where $\rho_{p}$ is the density of the particle used in the separator, $\rho_{f}$ is the density of the fluid medium used in the separator, $g$ is the gravitational constant.

The hydrodynamic magnetic force is larger than either of the com-

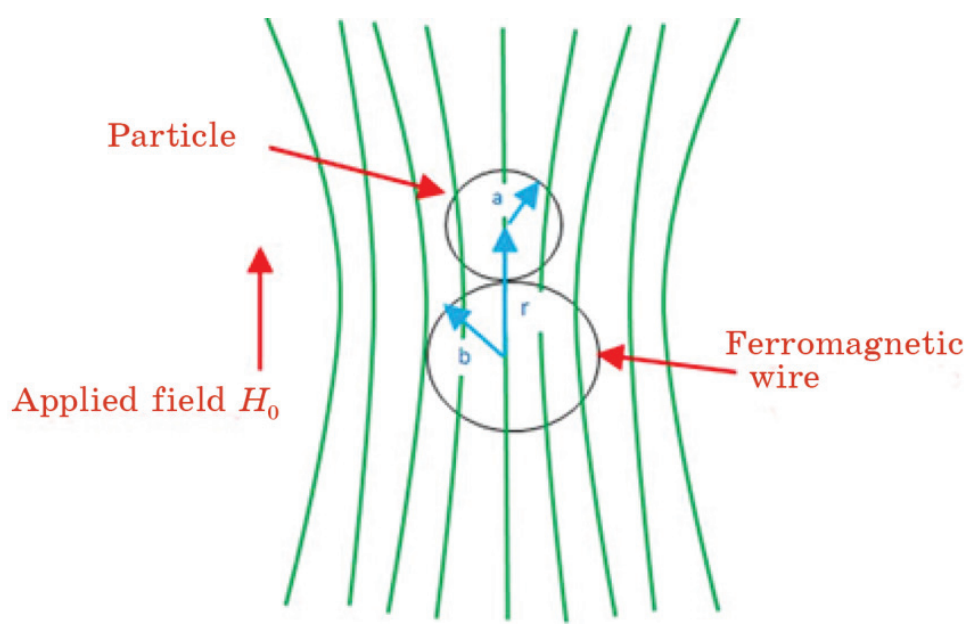

Fig. 5. Cross section of spherical particle. 
peting forces, drag force is given by:

$$
F_{d}=12 \pi \vartheta \vee b .
$$

In this relation $v$ is the kinematic viscosity of the fluid medium and $\vartheta$ is the velocity of the particle relative to the stream and it applies in the Stokes region. The dependence of the gravitational force on the third power of the particle radius means that the gravitational force will be significant for large particles. The hydrodynamic drag force, which in the Stokes regime depends on the first power of the particle radius, will be important for small particles. Thus in a magnetic separator which treats large particles in dry form, the feed material might be passed through the separator under the force of gravity.

The magnetic forces would have to be sufficient to hold the magnetic particles against the competing force of gravity. In wet separator for small particles the magnetic force would have to be larger than the hydrodynamic drag force which the slurry stream would exert on the trapped particles.

\section{RESULTS AND DISCUSSIONS}

The measurements of the induction and the $H$-gradient calculations of the field of the studied matrices showed us that these magnetic parameters weaken rapidly while moving towards the bottom of the teeth of the magnetic poles. From the curves drawn from the gradient $H$ we notice that the maximum values are close to the vertices, (see Table 1 results), and going down to the flat pole the gradient decreases successively in the direction of the measurement points $a^{\prime} \rightarrow a, b^{\prime} \rightarrow b, c^{\prime} \rightarrow c$, $g^{\prime} \rightarrow g$, to the angle that connects the two groups of teeth. This is explained by the increase in the distance of the curvatures of the force lines between these poles where we distinguish the distribution with more freedom. The equipotential lines of the magnetic forces coming out of the surfaces and focusing perpendicularly are usually concentrated on the vertices of the poles. For the creation of good conditions for obtaining maximum values of the magnetic force gradient $H$, it is necessary to use for the matrices profiles or groups of convex teeth are in faces of those concaves. By this way one obtains the two convex and concave parts face to face of each pole where it is necessary that the axis of symmetry of the convexity of one of the poles is confounded with the bisector of the angle of the concavity of the other pole. For the improvement of the technology of preparations of these forms it is sufficient only to take the top in angular form and the other teeth on the lateral plane of flat shapes. The essential method of finding the optimal form of fast demagnetization cores is that of mathematical modelling with programs and software for the different possible forms of 
equipotential lines such as Solid Works or CATIA.

The analysis of the phenomenon of concentration of the field which is at the top of teeth. It is also explained by the tendency of these curved lines to those directed towards the nearest surface perpendicularly. Thanks to the openings between the magnetic particles, the quality of the product extracted after the washing process is better and cleaner and the washing is very convenient to achieve. For a good distinction between the qualities of the magnetic fractions obtained we chose the size classes for our experiments (Fig. 6). Depending on the size, the residues are separated by particle size class (with a particle diameter less than $0.1 \mathrm{~mm}$ with an amount less than $75 \%$ ) and powdery.

The variation of the characteristics of the magnetic field with respect to the shapes of a tooth of acute poles of different angles of work. It can be seen that with the reduction of the working angle of the tooth, the in homogeneity of the field increases, which causes the increase of the force. The magnetic forces acting on the materials are generally very low for paramagnetic materials or diamagnetic. These forces derive from a volume magnetic energy acquired by the material in the presence of an applied magnetic field.

The material is said to be diamagnetic when the atomic or molecular layers are saturated, the resulting magnetic moment is zero. These materials nevertheless have a magnetic effect when subjected to a mag-

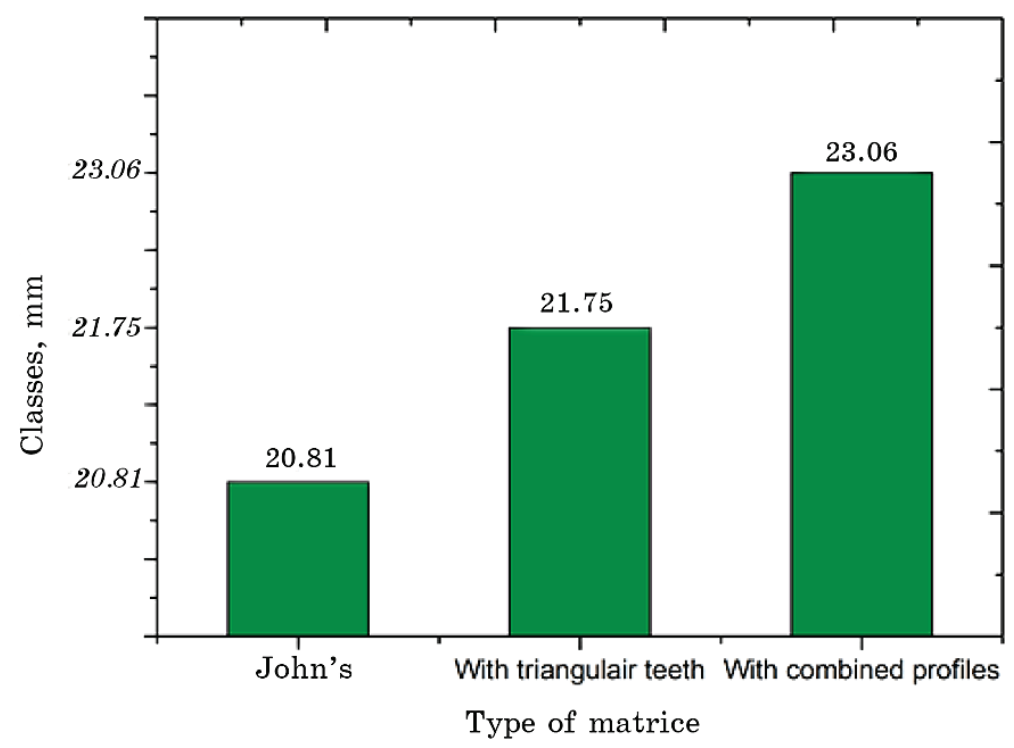

Fig. 6. Matrices used in the analysis of the magnetic field: $a$-John's matrices, $b$-proposed triangular tooth matrices, $c$-matrices with combined profiles. 
netic field: they will be pushed back by an intense field.

The electronic orbits are modified under the effect of the applied

TABLE 1. Influence of pole shapes on the parameters of the magnetic field following the change in the distance between the poles.

$a$-John's matrices.

\begin{tabular}{|c|c|c|c|}
\hline $\begin{array}{c}X \\
\text { In the direction of the point }(\mathrm{mm})\end{array}$ & $B, \mathrm{~T}$ & $H, \mathrm{kA} / \mathrm{m}$ & $\begin{array}{l}\operatorname{grad} H \cdot 10^{3} \\
\mathrm{kA} / \mathrm{m}^{2}\end{array}$ \\
\hline$a$ to $a^{\prime}$ & 0.133 & 105 & 0.636 \\
\hline$b$ to $b^{\prime}$ & 0.129 & 102 & 1.432 \\
\hline$c$ to $c^{\prime}$ & 0.120 & 95 & 1.909 \\
\hline$d$ to $d^{\prime}$ & 0.108 & 85 & 1.591 \\
\hline$e$ to $e^{\prime}$ & 0.098 & 77 & 0.795 \\
\hline$f$ to $f^{\prime}$ & 0.093 & 74 & 0.750 \\
\hline$g$ to $g^{\prime}$ & 0.082 & 65 & 0.636 \\
\hline
\end{tabular}

$b$-proposed triangular tooth matrices.

\begin{tabular}{cc|c|c|c}
\hline $\begin{array}{c}X \\
\text { In the direction of the point }(\mathrm{mm})\end{array}$ & $B, \mathrm{~T}$ & $H, \mathrm{kA} / \mathrm{m}$ & $\begin{array}{c}\mathrm{grad} H \cdot 10^{3} \\
\mathrm{kA} / \mathrm{m}^{2}\end{array}$ \\
\hline 5 & $a$ to $a^{\prime}$ & 0.105 & 83 & 0.795 \\
10 & $b$ to $b^{\prime}$ & 0.110 & 87 & 1.273 \\
15 & $c$ to $c^{\prime}$ & 0.102 & 81 & 1.909 \\
20 & $d$ to $d^{\prime}$ & 0.090 & 71 & 3.183 \\
25 & $e$ to $e^{\prime}$ & 0.070 & 55 & 0.795 \\
30 & $f$ to $f^{\prime}$ & 0.065 & 51 & 2.387 \\
35 & $g$ to $g^{\prime}$ & 0.050 & 39 & 0.954 \\
\hline
\end{tabular}

$c$-matrices with combined profiles.

\begin{tabular}{cc|c|c|c}
\hline $\begin{array}{c}X \\
\text { In the direction of the point }(\mathrm{mm})\end{array}$ & $B, \mathrm{~T}$ & $H, \mathrm{kA} / \mathrm{m}$ & $\begin{array}{c}\mathrm{grad} H \cdot 10^{3}, \\
\mathrm{kA} / \mathrm{m}^{2}\end{array}$ \\
\hline 5 & $a$ to $\mathrm{a}^{\prime}$ & 0.170 & 135 & - \\
10 & $b$ to $b^{\prime}$ & 0.180 & 143 & 1.591 \\
15 & $c$ to $c^{\prime}$ & 0.150 & 119 & 4.774 \\
20 & $d$ to $d^{\prime}$ & 0.120 & 95 & 4.774 \\
25 & $e$ to $e^{\prime}$ & 0.105 & 83 & 2.387 \\
30 & $f$ to $f^{\prime}$ & 0.082 & 65 & 3.660 \\
\hline
\end{tabular}

$X$ is the distance from the pole of the South acute matrix to the North Pole; $B$-induction of the magnetic field; $H$-intensity of magnetic field. 
magnetic field, and a magnetic moment is induced parallel to the applied field, in opposite directions, with a modulus proportional to the magnetic excitation. In the case where the atom has an incomplete electronic layer, it has a non-zero magnetic moment. When the thermal energy is stronger than the interaction energy of these magnetic moments, or when they do not interact with each other, the material is called paramagnetic. In zero fields, the directions of the moments are random, and the material does not have any resulting magnetization.

Figure 7 shows the evolution of the gradient of the field $H$, as a function of the distance between the poles for the three types of matrix. The matrix $c$ has recorded a high gradient $H$ for a short distance between poles, which leads to a consumption of one more energy, as the distance increases the energy, tends towards a decrease for the three matrices. On the other hand, the matrix $b$ gives us a weak gradient $H$ with respect to the others consequently less energy.

For the comparison of the technological indices of the magnetic separation and the determination of the disadvantages and for the clarification on the advantages of one type of matrix compared to another aiming at the creation more or less of the same magnetic separation conditions, we took for all types of matrix the same average magnetic induction between these poles. It is clear that because of the different shapes of the poles and their arrangements, and because of the coefficient of filling of the volume between the ferromagnetic poles, really, the magnetic potential and its induction more precisely will also be different.

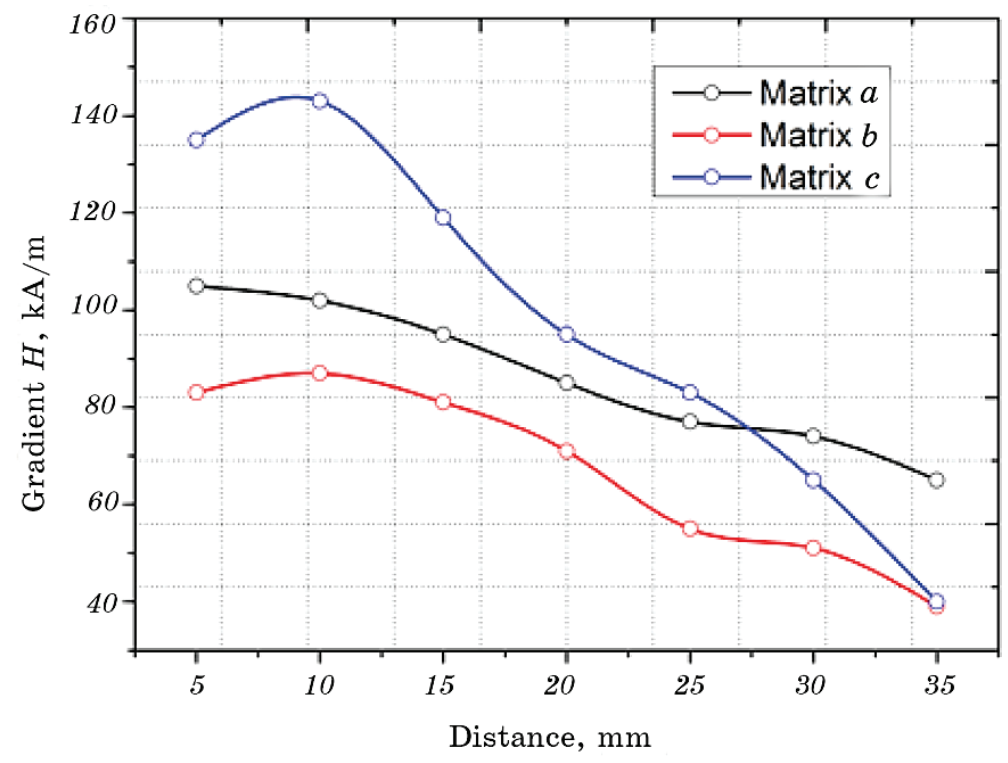

Fig. 7. Maximum values of gradient $H$. 
TABLE 2.Comparison of the high-gradient magnetic separation results of different classes of hematite ore (Algerian) by the three matrices used the magnetic induction of work is of $B=1.0 \mathrm{~T}$.

\begin{tabular}{|c|c|c|c|c|c|c|c|}
\hline \multicolumn{2}{|r|}{ Matrice } & Indices & $\begin{array}{c}\text { Classes }(\mathrm{mm}) \\
0.074+0.063\end{array}$ & $\begin{array}{c}\text { Classes }(\mathrm{mm}) \\
0.063+0.044\end{array}$ & \begin{tabular}{|c|} 
Classes \\
$(\mathrm{mm})$ \\
0.044
\end{tabular} & Sum & $\begin{array}{c}\text { Non- } \\
\text { magnetic } \\
\text { fraction }\end{array}$ \\
\hline \multirow[b]{3}{*}{$a$} & \multirow[b]{3}{*}{ John's } & ${ }^{\prime} \mathrm{Y}_{0 \text { (initial) }}$ & 37 & 27.6 & 35.4 & 100 & \\
\hline & & $\beta_{0 \text { (initial) }}$ & 40 & 44.1 & 47.8 & 43.9 & \\
\hline & & $\begin{array}{l}{ }^{\prime} \mathrm{Y} \\
\beta \\
\varepsilon\end{array}$ & $\begin{array}{c}20.81 \\
48.4 \\
22.94\end{array}$ & $\begin{array}{c}16.18 \\
58.2 \\
19.72\end{array}$ & $\begin{array}{c}17.52 \\
52.7 \\
21.04\end{array}$ & $\begin{array}{c}54.61 \\
51.21 \\
63.7\end{array}$ & $\begin{array}{c}45.39 \\
35.10 \\
-\end{array}$ \\
\hline$b$ & $\begin{array}{l}\text { With tri- } \\
\text { angular } \\
\text { teeth (in } \\
\text { this work) }\end{array}$ & $\begin{array}{l}{ }^{\prime} \mathrm{Y} \\
\beta \\
\varepsilon\end{array}$ & $\begin{array}{c}21.75 \\
49.6 \\
24.57\end{array}$ & $\begin{array}{c}17.2 \\
53.6 \\
21.00\end{array}$ & $\begin{array}{c}18.29 \\
52.9 \\
22.03\end{array}$ & $\begin{array}{c}57.24 \\
91.8 \\
67.60\end{array}$ & $\begin{array}{c}42.76 \\
33.33 \\
-\end{array}$ \\
\hline & $\begin{array}{l}\text { Combined } \\
\text { profiles (in } \\
\text { this work) }\end{array}$ & $\begin{array}{l}' \mathrm{Y} \\
\beta \\
\varepsilon\end{array}$ & $\begin{array}{l}23.06 \\
51.30 \\
26.94\end{array}$ & $\begin{array}{c}17.9 \\
54.40 \\
22.18\end{array}$ & $\begin{array}{l}19.95 \\
55.80 \\
25.35\end{array}$ & $\begin{array}{l}60.91 \\
53.67 \\
74.47\end{array}$ & $\begin{array}{c}39.09 \\
28.67 \\
-\end{array}$ \\
\hline
\end{tabular}

'Y-separation efficiency in $\% ; \beta$-iron content in $\% ; \varepsilon$-degrees of extraction in $\%$.

TABLE 3. Comparison of the high-gradient magnetic separation results of different classes of hematite ore (Algerian) by the three matrices used the magnetic induction of work is of $B=1.5 \mathrm{~T}$.

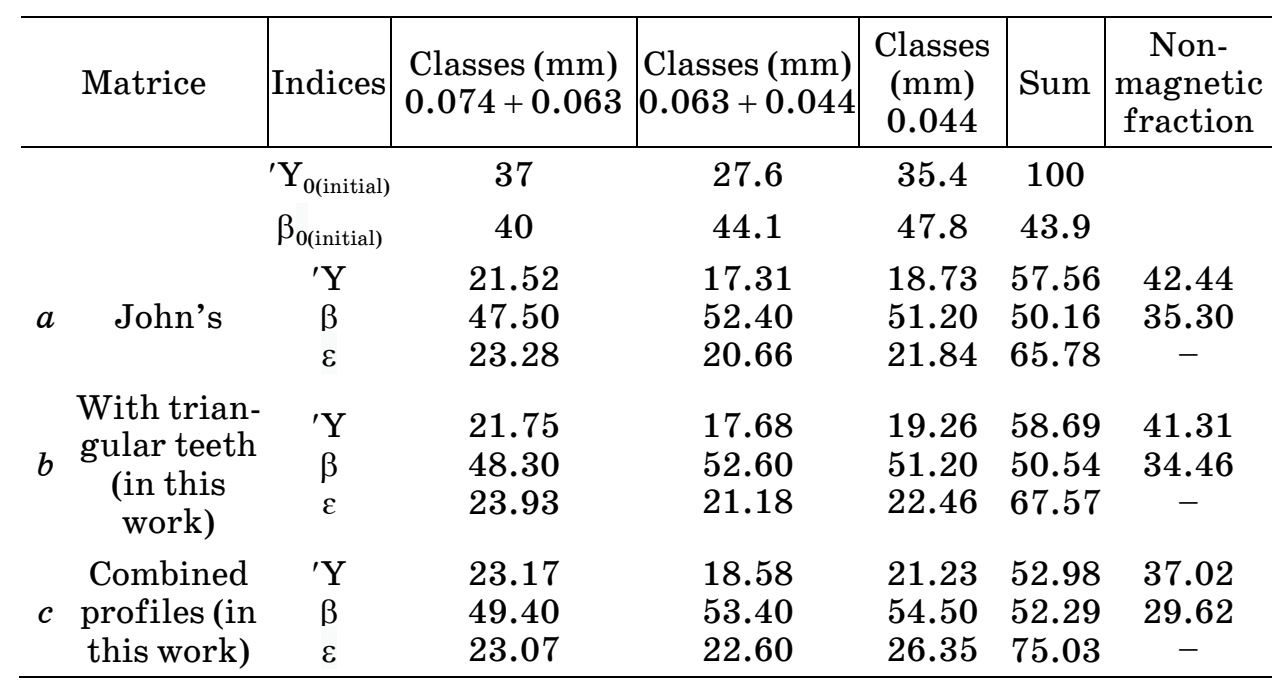


TABLE 4. Comparison of the high-gradient magnetic separation results of different classes of hematite ore (Algerian) by the three matrices used. The magnetic induction of work is of $B=2.0 \mathrm{~T}$.

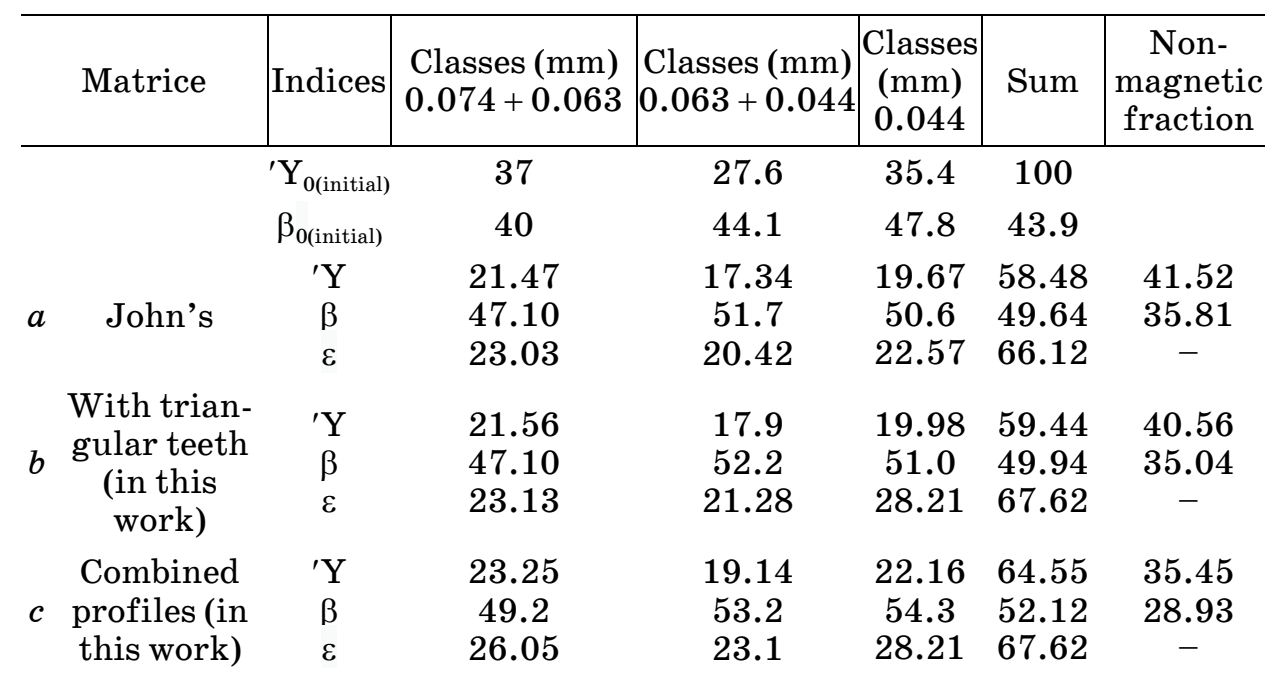

The experiments are conducted with a magnetic induction $B$ between the poles of equal value $1,1.5$, and $2 \mathrm{~T}$.

The separating product was first grinded to the $0.074 \mathrm{~mm}$ class for chemical analyses and the comparison of the magnetic enrichment efficiency of its different particle size classes (see Tables 2 and 3). The results of the experiments show that for the matrix $(b)$ with triangular teeth in comparison with the matrix ( $a$ ) of John's, and also for the matrix $(c)$ with combined profiles in comparison also with the matrix $(a)$ of John's, with an induction between the poles $1.5 \mathrm{~T}$. The quality of the magnetic fraction and the percentage of extraction in Iron for all the classes are superior it is the expected result. This shows in more than with the proposed matrix $(c)$ the separation of the fine class $(0.044$ $\mathrm{mm}$ ) gave a degree of extraction 5\% greater compared to the John's matrix, which proves a high technological efficiency the use of the proposed matrix.

The results of separation show (see Table 4) that with an upper induction between the poles $B=2 \mathrm{~T}$ applied to the matrices and for all the granulometric classes act according to the usual laws that is to say with the increase of the induction the degree of iron extraction increases, but the quality of the magnetic product decreases.

\section{CONCLUSION}

The series of tests applied to the different matrices in order to improve 
the efficiency of the extraction of ores, we used three types of matrices-John's matrices, proposed matrices with triangular teeth and Matrices with combined profiles.

The study conducted is based on the use of the method of highgradient magnetic separation for weakly magnetic particles. The action provided on the profile of the matrices consequently leads to changes in the separation distance which causes a variation in the intensity of the gradient of the magnetic field. The opted shape of the matrices, which is the matrix with triangular teeth a, makes it possible to give better results of one side of improvement of the intensity of the magnetic field gradient as a result, a finer extraction of the particles on the other side to increase the rate of extraction for varieties of particle sizes and shapes. The findings that we have detected on the choice of this type of matrix are as follows.

- Magnetic forces at the top of the matrix that is not optimal since there are large concentrations of field. But for the lateral parts of teeth, the field lines come out of the lower surfaces where the space remains empty devoid of magnetic floccules during the separation. It is for this reason that the gradient $H$ to decrease rapidly while going down the teeth and the area of distribution of the field to decrease.

- With the decrease of the angle of the acute pole, the in homogeneity of the field increases, which causes the increase of the gradient of the field.

- The combined forms for the creation of good conditions for obtaining maximum values of the magnetic force $\sim H \operatorname{grad} H$. Just as it is necessary to use profiles of the matrix where the groups of convex teeth are in front of those concave, as the compound of sharp, flat teeth.

- For the improvement of the technology of preparations of these forms it is enough only to take the top in triangular form and the other teeth on the lateral plane of flat shapes.

Finally, the process in this method finds its extension to the resolutions of the magnetic separation problems for the decontamination of the grounds and acts in a direct way on the environment following a significant reduction of the external pollution rate and also a higher rate of extraction of minerals.

\section{ACKNOWLEDGEMENTS}

The authors would like to thank Pr. Bahri Deghfel, Physics Department, Faculty of Sciences, University of Mohamed Boudiaf, M'sila (Algeria) for his help. He made a review and read this article. The authors would also like to thank the engineers from the laboratory of high-gradient magnetic field separation of the National University of Kryvyi Rih (Ukraine) for the use of the materials. 


\section{REFERENCES}

1. L. R. Avens, L. A. Worl, K. J. DeAguero, D. D. Padilla, F. C. Prenger, W. F. Stewart, D. D. Hill, and T. L. Tolt, Abstr. Conf. Magnetic Separation for Soil Decontamination (28 Feb-4 Mar, 1993, United States).

2. A. Matsuzaki and S. Nagakura, Journal of Luminescence, 12: 787 (1976).

3. T. Kakeshita, K. Shimizu, S. Funada, and M. Date, Acta Mater., 33, No. 8: 1381 (1985).

4. Y. Xu, J. Chen, B. Jiang, Y. Liu, and J. Ni, Int. J. Mech. Sci., 142: 86 (2018).

5. J. Torbet, J. M. Freyssinet, and G. Hudry-Clergeon, Nature, 289: 91 (1981).

6. W. Ge, A. Encinas, E. Araujo, and S. Song, Results Phys., 7: 4278 (2017).

7. S. Miltenyi, W. Müller, W. Weichel, and A. Radbruch, Cytom. A, 11, No. 2: 231 (1990).

8. C. T. Yavuz, J. T. Mayo, W. Y. William, A. Prakash, J. C. Falkner, S. Yean, and D. Natelson, Science, 314 (5801): 964 (2006).

9. J. J. Hubbuch, D. B. Matthiesen, T. J. Hobley, and O. R. Thomas, Bioseparation, 10: 99 (2001).

10. M. A. M. Gijs, Microfluid. Nanofluid., 1: 22 (2004).

11. J. Svoboda, and T. Fujita, Miner. Eng., 16: 785 (2003).

12. R. R. Dauer and E. H. Dunlop, Biotechnol. Bioeng., 37: 1021 (1991).

13. A. M. Turkenich, Physical Separation in Science and Engineering, 10: 207 (2001).

14. J. Svoboda, Miner. Eng., 14: 1493 (2001).

15. V. Karmazin, Magnitnye, Elektricheskie i Spetsialnye Metody Obogashcheniya Poleznykh Iskopaemykh (Moscow: Gornaya Kniga: 2017). ISBN: 978-5-98672458-4.

16. V. I. Karmazin and V. V. Karmazin, Magnitnye i Elektricheskie Metody Obogashcheniya. Uchebnik dlya Vuzov (Moscow: Nedra: 1988). ISBN 5-24700169-9.

17. S. G. Ozkan, Magn. Electr. Separ., 10: 213 (2001).

18. K. P. Ossenkopp, Psychol. Rep., 30: 371 (1972).

19. L. Woltjer, Proc. Natl.Acad.Sci., 44, 489 (1958).

20. P. Démoulin and M. A. Berger, Sol. Phys., 215: 203 (2003). 